\title{
The Effect of Ageing on Nasal Mucociliary Clearance in Women: A Pilot Study
}

\author{
Preetha Paul, ${ }^{1}$ Priscilla Johnson, ${ }^{2}$ Padmavathi Ramaswamy, ${ }^{2}$ Sitalakshmi Ramadoss, \\ Bagavad Geetha, ${ }^{2}$ and A. S. Subhashini ${ }^{2}$ \\ ${ }^{1}$ Department of Physiology, Tagore Medical College, Chennai 600 127, India \\ ${ }^{2}$ Department of Physiology, Sri Ramachandra Medical College, Chennai 600 116, India
}

Correspondence should be addressed to Preetha Paul; drpreethapaul@yahoo.co.in

Received 26 January 2013; Accepted 6 March 2013

Academic Editors: A. Celi, A. Comellas, T. J. Kelley, and A. S. Melani

Copyright (C) 2013 Preetha Paul et al. This is an open access article distributed under the Creative Commons Attribution License, which permits unrestricted use, distribution, and reproduction in any medium, provided the original work is properly cited.

Introduction. Pneumonia is the leading infectious cause of death in the elderly. Impaired respiratory defences are one of the causes for increased susceptibility of the elderly to such infections. Nasal mucociliary clearance, the mirror image of bronchial clearance, is crucial in respiratory defence and is affected by various factors. Little is known about the effect of ageing on nasal respiratory epithelium. Aim. To evaluate the effect of ageing on nasal mucociliary clearance (NMC) in women. Materials and Methods. NMC was measured in 91 apparently healthy women of ages ranging from 20 to 80 years. The time taken to experience sweet taste at nasopharynx following the placement of saccharin pellet in the nostril was recorded as NMC time. Results and Discussion. NMC time was 10 min 36 secs in elderly women and it was significantly prolonged when compared to younger women ( 8 min 39 secs). The prolonged clearance may be due to altered cilia, slowed ciliary beating, or changes in the properties of mucus. Conclusion. NMC time clearly shows an increase with age signifying decreasing respiratory epithelium function. This study highlights an important cause of impaired respiratory health in older individuals and emphasises the need for preventive measures to be put in place.

\section{Background}

Elderly individuals are particularly prone to infections such as pneumonia and this has been found to be a major cause of mortality among them [1]. Although the increased susceptibility of the elderly to respiratory infections has not been fully explained, impaired defence mechanisms may be one of the causative factors along with alterations in pulmonary structure and function associated with the normal ageing process.

Nasal mucociliary clearance (NMC) is a primary innate defence mechanism of the nose and paranasal sinuses whereby mucus secreted into the upper airways (by the goblet cells of the respiratory epithelium) traps inhaled particulate matter, allergens, and pathogens [2] and is then transported with the trapped matter (by the ciliated cells of the respiratory epithelium which beat at a frequency of 12 to $15 \mathrm{~Hz}$ ) [3] to the pharynx, where it is swallowed [4]. NMC is the mirror image of bronchial mucociliary clearance [5] and the ciliary beat frequency of nasal mucosa correlates with that of tracheal mucosa [6,7]. NMC is influenced by physiological factors such as the amount of mucus produced and the ciliary beat efficiency, anatomic factors such as nasal airflow and patency of the sinus ostia in the prechambers, and biochemical factors such as mucus composition [4].

Impairment of NMC results in the accumulation of respiratory secretions and reduced lung defenses leading to infections, inflammation [4], and perhaps even neoplasia [8]. NMC thus functions as a biomarker of nasal mucosal function [9] and can serve as an early warning system for susceptibility to respiratory diseases.

Very little information is available regarding NMC and the effect of age on this defence mechanism. This study was therefore done to assess the effect of age on nasal mucociliary clearance in a population of rural women and to investigate whether factors other than age such as type of cooking fuel used, literacy status, or socioeconomic status may have an effect on NMC. 


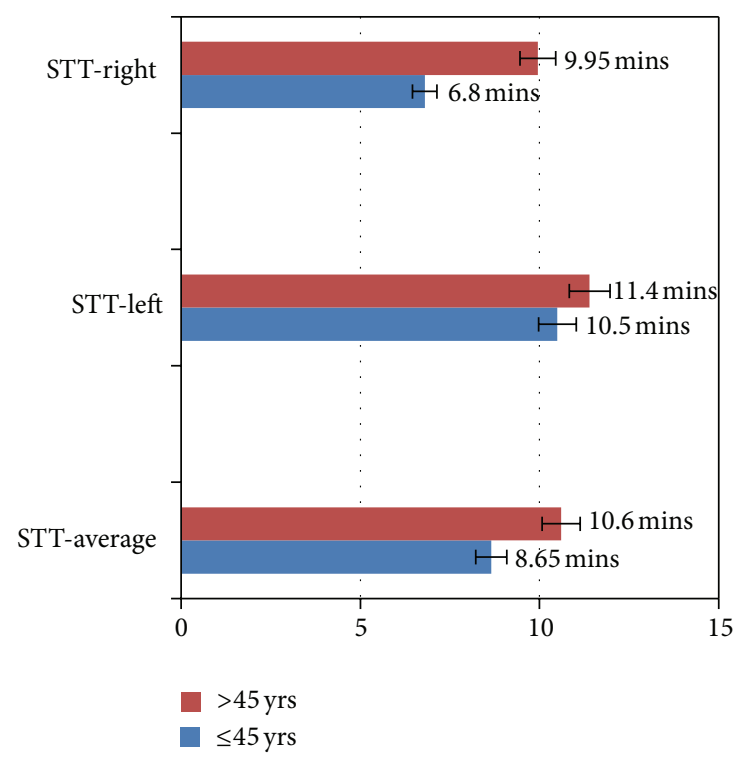

Figure 1: Comparison of Saccharine Transit Time between the two age categories.

\section{Aim and Objectives}

The objects of this paper are to evaluate the effect of ageing on nasal mucociliary clearance in women and to find out whether factors other than age such as literacy status, socioeconomic status, and type of fuel used for cooking may have an effect on NMC.

\section{Materials and Methods}

This was a cross-sectional study carried out among women in Paraniputhur, Kundrathur, and Kulathuvanchery villages of Kanchipuram district, Tamil Nadu, India. Institutional Ethical Clearance from the institution and permissions from the governing heads of the particular villages were obtained for conducting the study.

A total of 152 women were screened by door-to-door visits and detailed history regarding allergies, respiratory disorders, systemic disease, local pathology, impairment of taste sensation, and use of medication was obtained from each using a screening questionnaire. Apparently healthy women of ages ranging from 20 to 80 years were selected for the study. Smokers, passive smokers, tobacco chewers, and snuff users were excluded from the study. Women who had local pathology such as deviated nasal septum, nasal polyp, nasal allergy, rhinosinusitis, and respiratory/nasal symptoms (within the preceding two weeks) and women with self-reported diabetes/other chronic or systemic diseases, bronchiectasis, valvular heart disease, bleeding diatheses, and intake of any medication(s) (particularly antihistaminics) were also excluded. On the basis of the exclusion criteria, 43 women were excluded. Eighteen refused to participate in the study for personal reasons. Ninety-one apparently healthy subjects volunteered to participate in the study.
TABLE 1: Descriptive characteristics of the study population.

\begin{tabular}{lcccc}
\hline Variables & $\begin{array}{c}\text { Age } \\
\leq 45 \text { years }\end{array}$ & Percentage & $\begin{array}{c}\text { Age } \\
>45\end{array}$ years & Percentage \\
\hline $\begin{array}{l}\text { Total number of } \\
\text { Subjects }\end{array}$ & 69 & & 22 & \\
\hline $\begin{array}{l}\text { Education } \\
\quad \text { Literate }\end{array}$ & 51 & 73.9 & 13 & 59.1 \\
$\quad$ Illiterate & 18 & 26.1 & 9 & 40.9 \\
\hline Occupation & & & & \\
$\quad$ Homemaker & 48 & 69.6 & 14 & 63.6 \\
$\quad$ Employed & 21 & 30.4 & 8 & 36.4 \\
\hline House Type & & & & \\
$\quad$ Pucca & 26 & 37.7 & 15 & 68.2 \\
$\quad$ Kutcha & 43 & 62.3 & 7 & 31.8 \\
\hline Income per annum & & & & \\
$\quad$ Rs.25000 & 63 & 91.3 & 11 & 50 \\
$\quad<$ Rs.25000 & 6 & 8.7 & 11 & 50 \\
\hline Cooking fuel type & & & & \\
$\quad$ Clean fuel & 36 & 52.2 & 13 & 59.1 \\
$\quad$ Biomass fuel & 33 & 47.8 & 9 & 40.9 \\
\hline
\end{tabular}

A study questionnaire that included questions regarding occupation, education, income, cooking fuel type, and housing type was administered.

NMC assessment was done using a simple, quick, noninvasive, and reproducible test, namely, Andersen's Saccharine Transit Test [5].

With the subject in sitting position with her neck slightly flexed, a $1 \mathrm{~mm} \times 1 \mathrm{~mm} \times 1 \mathrm{~mm}$ pellet of saccharine was placed on the floor of the nose, just behind the anterior end of the inferior turbinate. The time taken by the subject to perceive the sweet taste was noted as Saccharine Transit Time (STT). The test was carried out on both sides with a half hour interval in between and the values were recorded as STTL and STTR. The average of these two values (STTav) was computed and taken as nasal mucociliary clearance time. The subjects were not informed about the nature of the particle and were simply asked to report the taste perceived.

Data analysis was done using the Student's $t$ test and statistical significance was taken as $P<0.05$.

\section{Results}

Study subjects were grouped into two categories for analysis: age $\leq 45$ years ( 69 subjects) and age $>45$ years ( 22 subjects).

All the three values STT-left, STT-right, and STT-average were found to be higher in the older age group compared to the younger one (Figure 1 and Table 2). The mean STT on the left side (STT-left) in the $>45$ age group was found to be 11.4 mins while in the $\leq 45$ age group, it was 10.5 mins. Mean STT-right (Saccharine Transit Time-Right) in the older age group was 9.95 mins while in the younger age group it was 


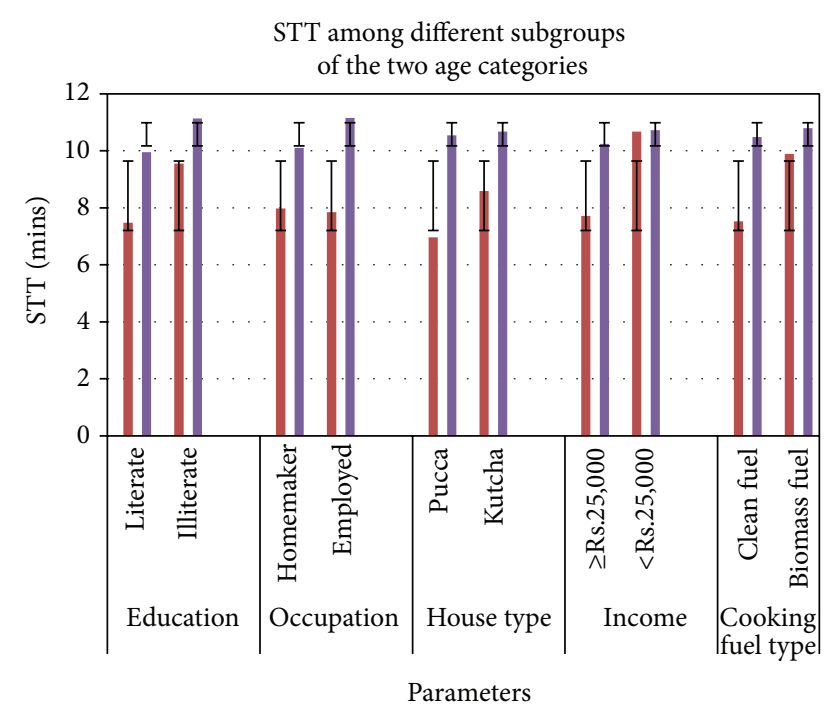

- Age $\leq 45 \mathrm{yrs}$

- Age $>45 \mathrm{yrs}$

FIGURE 2

TABle 2: Comparison of Saccharine Transit Time between the two age categories.

\begin{tabular}{lcccc}
\hline & Age group (Yrs) & $N$ & Mean (mins) & Std. deviation \\
\hline \multirow{2}{*}{ STT-average* } & $\leq 45$ & 69 & 8.65 & 3.70 \\
& $>45$ & 22 & 10.6 & 1.68 \\
\hline \multirow{2}{*}{ STT-left } & $\leq 45$ & 69 & 10.5 & 5.33 \\
& $>45$ & 22 & 11.4 & 2.81 \\
\hline \multirow{2}{*}{ STT-right } & $\leq 45$ & 69 & 6.80 & 4.36 \\
& $>45$ & 22 & 9.95 & 1.71 \\
\hline
\end{tabular}

${ }^{*} P$ value is statistically significant.

STT: Saccharine Transit Time.

6.8 mins and this increase was statistically significant. Mean STTav was 10.6 mins in the $>45$ age group and 8.65 mins in the $\leq 45$ age group. This increase also was found to be statistically significant with a $P$ value of 0.020 .

The descriptive characteristics of the study population are given in Table 1. Comparing STT among the different subgroups of the younger and older age categories (Figure 2 and Table 3), the mean STT was found to be higher among illiterates compared to literates in both age groups though it was not statistically significant. In the $\leq 45$ age category, the homemaker group of women had a mean STT of $7.98 \pm$ 3.51 mins, while those employed outside the home timed $7.85 \pm 4.21$ mins. In the older age group, the homemakers' mean STT was $10.1 \pm 1.68 \mathrm{mins}$ and among the employed it was $11.16 \pm 1.56$ mins. Women living in kutcha houses showed a higher STT compared to those that lived in pucca houses. This was true for both age categories and the difference in the younger age group was found to be statistically significant. Women who used clean fuel for cooking had a lower mean STT compared to those who used biomass fuels in both age categories.
Among the different socioeconomic categories, the lower income group had a higher STT compared to the higher income group in both age categories. The mean STT among women in families having an annual income of less than Rs.25,000 in the $\leq 45$ age group was found to be $10.67 \pm$ 1.84 mins while it was $7.72 \pm 3.81$ in the higher income group. In the $>45$ age group, STT was $10.72 \pm 1.8$ mins among the lower income category and $10.24 \pm 1.58$ among those with higher incomes. This difference was found to be statistically significant $(P=0.0056)$ in the younger age group.

\section{Discussion}

Epidemiology has shown that the elderly are more susceptible to respiratory illness and advanced age appears to predispose older individuals to the increased severity of respiratory infections as well [1]. Although this might be explained by ciliary defects or impaired mucociliary clearance or physiologic/structural changes in the senescent lung, very little data exists on the effect of ageing on mucociliary clearance [10].

Our study showed that Saccharine Transit Time, which negatively reflects the efficiency of NMC, increases with increasing age. The mean STT was higher in the $>45$ age group when compared with that of the $\leq 45$ age group and this increase was found to be statistically significant.

Increased NMC time signifying a decline in mucociliary clearance could be attributed to a variety of anatomical, physiological, and biochemical changes which occur during the normal ageing process, which may affect the response of the lung to inhaled agents [1].

Anatomical changes that occur with ageing include nasal mucosal damage which has accumulated from infections over the years, ciliary ultrastructural defects such as the occurrence of increased central microtubular disorientation, age-related changes in lung morphology resulting in altered proportions of elastic tissues and collagen [10], and alterations in the cross-linkage of ageing collagen [11].

Physiological alterations that could impair mucociliary clearance include abnormally slow or uncoordinated ciliary beating where neighbouring cilia do not beat in a coordinated fashion and in the same direction. This could be the result of abnormal ciliary ultrastructure or occur de novo $[3,10]$. Additionally, quantitative and qualitative changes in respiratory mucus and a lower tracheal mucus velocity could be causes of impaired mucociliary clearance among the elderly [10].

Biochemical changes such as greater lung oxidative stress potential [12] may play a role as well.

Other potential factors that could affect mucociliary clearance include trauma, exposure to external toxin(s), and other unknown factors. These factors could either directly or indirectly lead to a decline in ciliary beat frequency and the occurrence of increased central microtubular disorientation with ageing, both of which adversely affect mucociliary clearance.

Our results are in accordance with those of Ho et al. [10] who studied NMC time along with ciliary beat frequency and ultrastructure of respiratory cilia, which are determinants of 
TABle 3: Comparison of Saccharine Transit Time among different subgroups of the younger and older age categories.

\begin{tabular}{|c|c|c|c|c|c|c|}
\hline \multicolumn{7}{|c|}{ Saccharine transit time (Mins) } \\
\hline \multirow{2}{*}{ Parameters } & \multicolumn{3}{|c|}{ Age $\leq 45$ years } & \multicolumn{3}{|c|}{ Age $>45$ years } \\
\hline & $N$ & $\begin{array}{l}\text { Mean } \\
\text { (mins) }\end{array}$ & SD & $N$ & $\begin{array}{l}\text { Mean } \\
\text { (mins) }\end{array}$ & SD \\
\hline \multicolumn{7}{|l|}{ Education } \\
\hline Literate & 51 & 7.48 & 3.69 & 12 & 9.95 & 1.38 \\
\hline Illiterate & 18 & 9.55 & 3.49 & 10 & 11.14 & 1.8 \\
\hline \multicolumn{7}{|l|}{ Occupation } \\
\hline Homemaker & 48 & 7.98 & 3.51 & 14 & 10.1 & 1.68 \\
\hline Employed & 21 & 7.85 & 4.21 & 8 & 11.16 & 1.56 \\
\hline \multicolumn{7}{|l|}{ House type } \\
\hline Pucca & 26 & $6.97^{*}$ & 2.71 & 15 & 10.54 & 1.76 \\
\hline Kutcha & 43 & 8.59 & 4.06 & 7 & 10.67 & 1.57 \\
\hline \multicolumn{7}{|l|}{ Income } \\
\hline$\geq$ Rs. 25000 & 63 & $7.72^{*}$ & 3.81 & 11 & 10.24 & 1.58 \\
\hline$<$ Rs. 25000 & 6 & 10.67 & 1.84 & 11 & 10.72 & 1.8 \\
\hline \multicolumn{7}{|l|}{ Cooking fuel type } \\
\hline Clean fuel & 36 & 7.53 & 3.42 & 13 & 10.48 & 1.32 \\
\hline Biomass fuel & 33 & 9.89 & 3.66 & 9 & 10.79 & 2.16 \\
\hline
\end{tabular}

the efficiency of ciliary action. They found that there was a significant difference between the NMC time for subjects under and over the age of 40 years and that there was a significant correlation between NMC time and age. This increase in NMC time with age may be due to the decrease in ciliary function with age as a result of increasing occurrence of ultrastructural defects in respiratory epithelial cilia.

The mean STT value of 8.65 mins obtained for the $\leq 45$ age group in our study was found to be comparable with normal STT values reported by other studies such as by Yadav et al. [13], Golhar [14], and Golhar and Arora [15].

Our study also found that NMC time is prolonged in biomass fuel users compared to clean fuel users. An earlier study by Priscilla et al. had already demonstrated the same and it is attributed to biomass-fuel-smoke-induced damage to the respiratory mucosa causing ciliary malfunction [16].

The study also found that NMC time is higher in those of low socioeconomic status than in those of higher socioeconomic status. This difference could be attributed to poor nutritional and health states, unhealthy living conditions and exposure to biomass fuel smoke, and perhaps other environmental toxins as well among those of the lower socioeconomic strata.

Additionally, NMC time was found to be higher among the illiterates indicating poorer mucociliary clearance in this group compared to those of higher literacy status. This could be a reflection of their poorer socioeconomic status which may be indirectly resulting in their being exposed to suspended particulate matter and toxins in the environment and owing to precautionary measures not being adopted both due to the lack of knowledge and the lack of means, causing deleterious effects to their health.

\section{Conclusion}

This study showed that NMC time increases with increasing age showing that lung defences by mucociliary clearance mechanisms are impaired with age. Impairment of NMC with age was found to be higher among lower socioeconomic status, lower literacy status, and biomass fuel users.

The study highlights the increased risk of respiratory diseases in older women so that awareness can be created among the general public and proper intervention strategies put in place. Preventive measures like health education will go a long way towards informing them about the risks of poor respiratory health and giving cautionary advice. This standard, simple, quick, inexpensive, and noninvasive test can be used for periodic assessment of NMC and can therefore serve as an early diagnostic pointer and pave the way for recognising the susceptibility to progression to respiratory diseases in elderly women at an early stage.

\section{Limitations of the Study}

(i) The study has been done only in women. Though some researchers have reported that there is no gender difference in NMC $[10,17]$, the study would have been more comprehensive had it included male subjects as well.

(ii) Small sample size: this is a preliminary study to assess the effect of age on NMC in a population of periurban women. A large scale study that excludes potential confounders such as biomass fuel users and occupational exposure to dust would yield better results.

(iii) Cross-sectional study design.

\section{References}

[1] J. M. Antonini, J. R. Roberts, R. W. Clarke et al., "Effect of age on respiratory defense mechanisms: pulmonary bacterial clearance in Fischer 344 rats after intratracheal instillation of Listeria monocytogenes," Chest, vol. 120, no. 1, pp. 240-249, 2001.

[2] M. A. Mall, "Role of cilia, mucus, and airway surface liquid in mucociliary dysfunction: lessons from mouse models," Journal of Serosol Medicine and Pulmonary Drug Delivery, vol. 21, no. 1, pp. 13-24, 2008.

[3] S. E. Houtmeyers, R. Gosselink, G. Gayan-Ramirez, and M. Decramer, "Regulation of mucociliary clearance in health and disease," The European Respiratory Journal, vol. 13, no. 5, pp. 1177-1188, 1999.

[4] N. A. Cohen, "Sinonasal mucociliary clearance in health and disease," The Annals of Otology, Rhinology \& Laryngology. Supplement, vol. 196, pp. 20-26, 2006.

[5] J. Yadav, A. Verma, and K. B. Gupta, "Mucociliary clearance in Bronchial Asthma," Indian Journal of Allergy, vol. 19, no. 1, pp. 21-23, 2005.

[6] J. Rutland, W. M. Griffin, and P. J. Cole, "Human ciliary beat frequency in epithelium from intrathoracic and extrathoracic 
airways," The American Review of Respiratory Disease, vol. 125, no. 1, pp. 100-105, 1982.

[7] A. B. Millar, J. E. Agnew, S. P. Newman, M. T. Lopez-Vidriero, D. Pavia, and S. W. Clarke, "Comparison of nasal and tracheobronchial clearance by similar techniques in normal subjects," Thorax, vol. 41, no. 10, pp. 783-786, 1986.

[8] Y. Li, S. J. Swensen, L. G. Karabekmez et al., "Effect of emphysema on lung cancer risk in smokers: a computed tomographybased assessment," Cancer Prevention Research, vol. 4, no. 1, pp. 43-50, 2011.

[9] R. Bascom, J. Kesavanathan, T. K. Fitzgerald, K. H. Cheng, and D. L. Swift, "Sidestream tobacco smoke exposure acutely alters human nasal mucociliary clearance," Environmental Health Perspectives, vol. 103, no. 11, pp. 1026-1030, 1995.

[10] J. C. Ho, K. N. Chan, W. H. Hu et al., "The effect of aging on nasal mucociliary clearance, beat frequency, and ultrastructure of respiratory cilia," The American Journal of Respiratory and Critical Care Medicine, vol. 163, no. 4, pp. 983-988, 2001.

[11] D. R. Sell, M. A. Lane, W. A. Johnson et al., "Longevity and the genetic determination of collagen glycoxidation kinetics in mammalian senescence," Proceedings of the National Academy of Sciences of the United States of America, vol. 93, no. 1, pp. 485490, 1996.

[12] A. C. P. Elder, R. Gelein, J. N. Finkclstein, C. Cox, and G. Oberdörster, "Endotoxin priming affects the lung response to ultrafine particles and ozone in young and old rats," Inhalation Toxicology, vol. 12, no. 1, pp. 85-98, 2000.

[13] J. Yadav, A. Verma, and J. Singh, "Study on nasal mucus clearance in patients of perennial allergic rhinitis," Indian Journal of Allergy, Asthma and Immunology, vol. 17, pp. 89-91, 2003.

[14] S. Golhar, "Nasal mucus clearance," Journal of Laryngology and Otology, vol. 100, no. 5, pp. 533-538, 1986.

[15] S. Golhar and M. M. L. Arora, "The effect of cryodestruction of Vidian nasal branches on nasal mucus flow in vasomotor rhinitis," Indian Journal of Otolaryngology, vol. 33, no. 1, pp. 1214, 1981.

[16] J. Priscilla, R. Padmavathi, S. Ghosh et al., "Evaluation of mucociliary clearance among women using biomass and clean fuel in a periurban area of Chennai: a preliminary study," Lung India, vol. 28, no. 1, pp. 30-33, 2011.

[17] P. Plaza Valía, F. C. Valero, J. M. Pardo, D. B. Rentero, and C. G. Monte, "Saccharin test for the study of mucociliary clearance: reference values for a Spanish population," Archivos de Bronconeumologia, vol. 44, no. 10, pp. 540-545, 2008. 


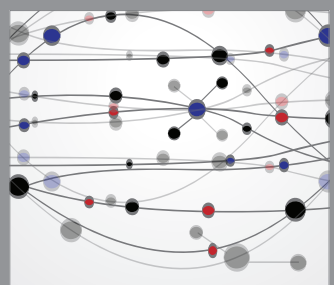

The Scientific World Journal
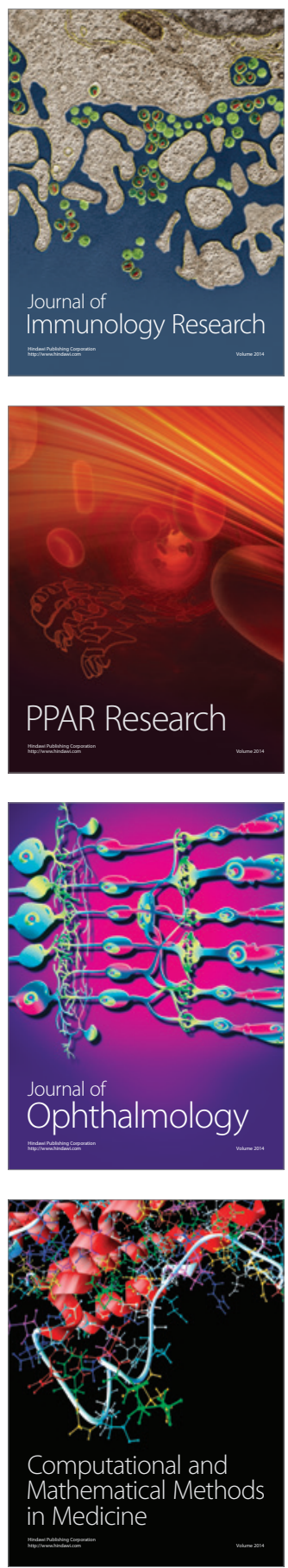

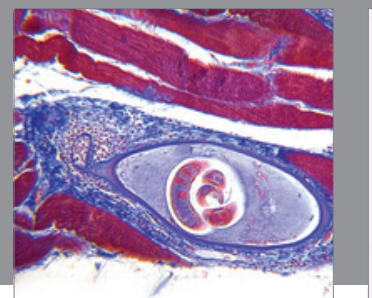

Gastroenterology

Research and Practice
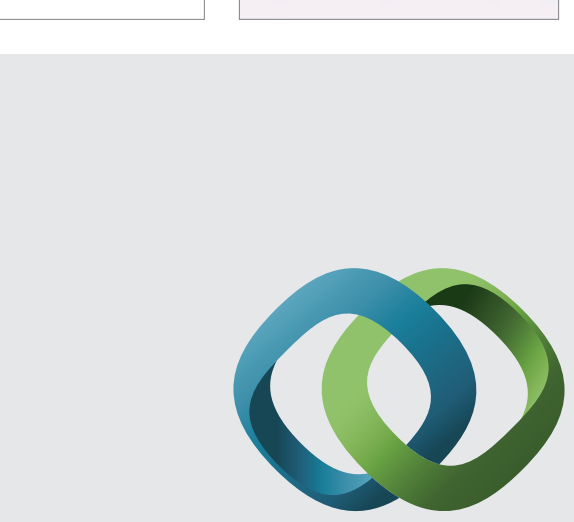

\section{Hindawi}

Submit your manuscripts at

http://www.hindawi.com
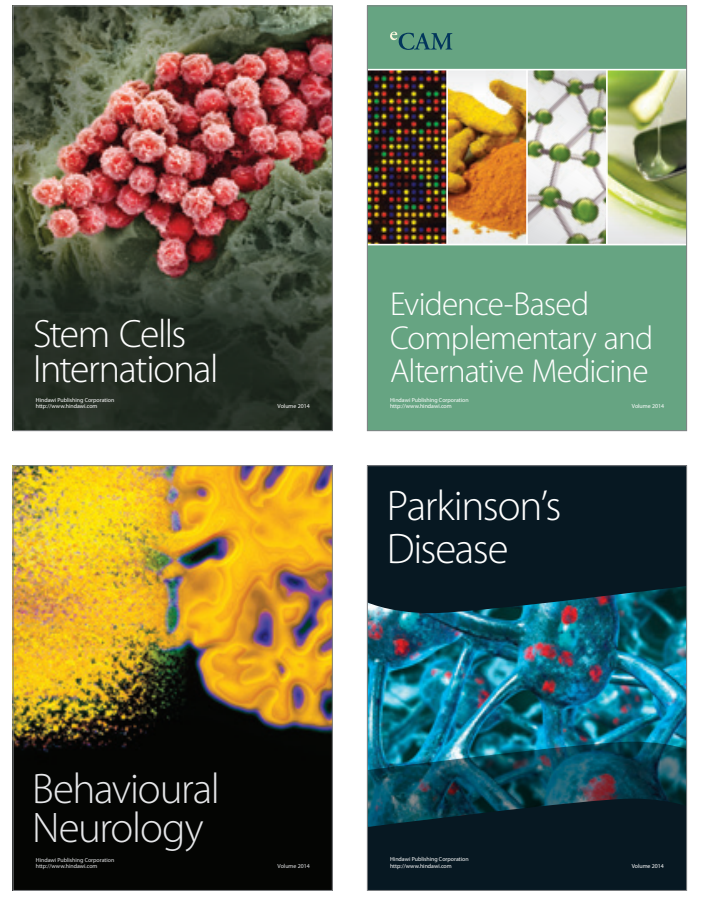
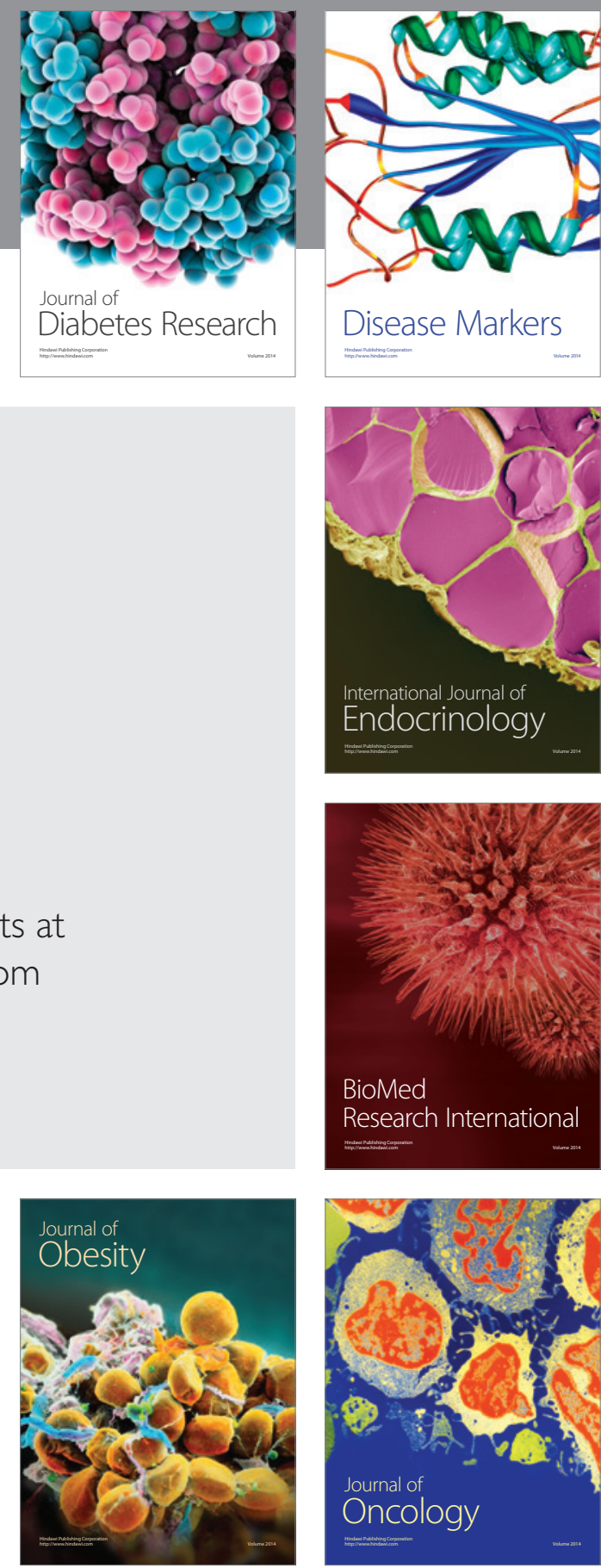

Disease Markers
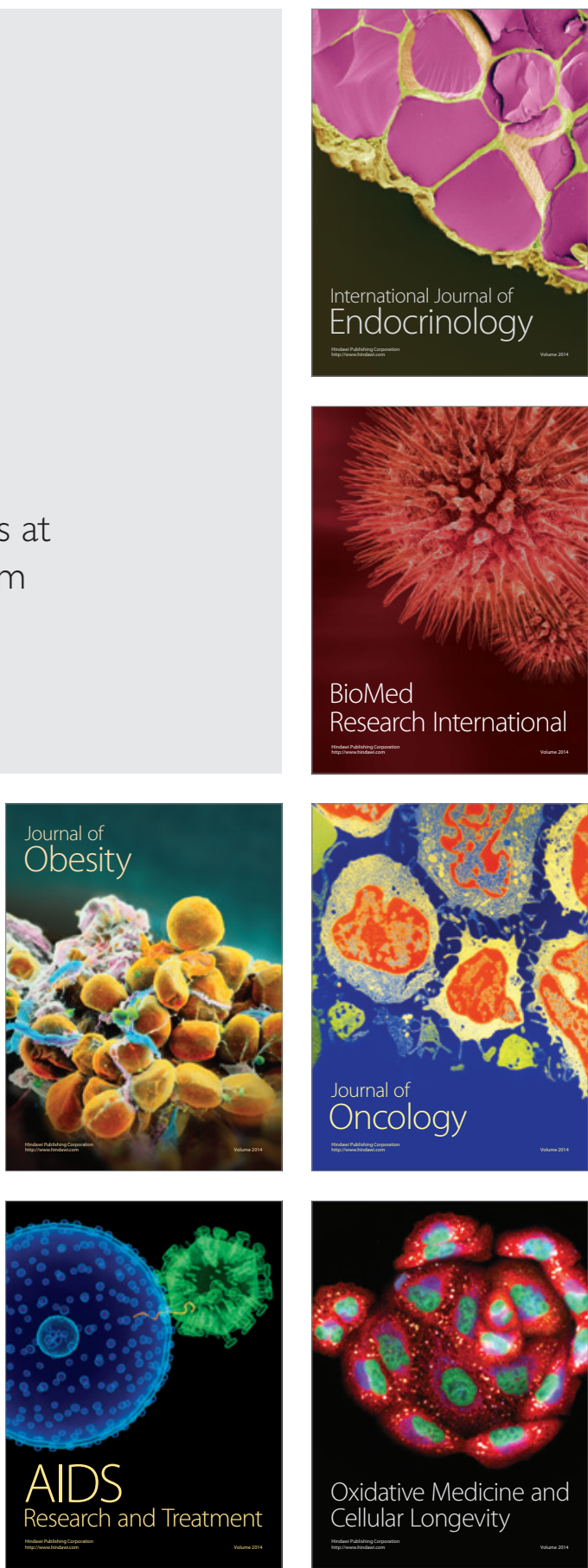